\title{
Study on Co-Opetition in China's Edible Mushroom Industry: Take Shandong Province as an Example
}

\author{
Min Li, Jilian Hu, Yanxiang Ge \\ School of Economics and Management, Shandong Agriculture University, Tai'an, China \\ Email: limin1988@163.com
}

How to cite this paper: $\mathrm{Li}, \mathrm{M} ., \mathrm{Hu}$ J.L. and Ge, Y.X. (2018) Study on Co-Opetition in China's Edible Mushroom Industry: Take Shandong Province as an Example. Modern Economy, 9, 1-14.

https://doi.org/10.4236/me.2018.91001

Received: November 27, 2017

Accepted: January 1, 2018

Published: January 4, 2018

Copyright (C) 2018 by authors and Scientific Research Publishing Inc. This work is licensed under the Creative Commons Attribution International License (CC BY 4.0).

http://creativecommons.org/licenses/by/4.0/

\section{(c) (i) Open Access}

\begin{abstract}
During the last few years, large-scale enterprises that engage in commercial cultivation of edible mushrooms have been growing at a very fast pace, bringing about new changes to the industrial structure of the edible mushroom industry. Co-existence of large-scale enterprises and small-scale farmers has become the long-term status quo of the edible mushroom industry. How to promote proportional development for these two important industrial bodies has become a pressing issue for the edible mushroom industry in Shandong Province. This paper studies Co-opetition in the edible mushroom industry in Shandong Province, in regard to aspects and effect on industrial competition pattern, motives, benefits, potential challenges and evolution of co-opetition. This paper concludes that by carrying out price insurance on edible mushrooms, developing intermediary organizations and reinforcing government support, co-opetition between the two will become more efficient, which in turn, will promote the evolution to the mode of "balanced co-opetition" and optimize the organization of the edible mushroom industry.
\end{abstract}

\section{Keywords}

Edible Mushrooms, Co-Opetition, Large-Scale Enterprises in Edible Mushrooms Industry, Small-Scale Farmers, Industrial Competition Pattern Transformation, Price Insurance, Intermediary Organizations

\section{Introduction}

Competition and cooperation has long been two independent fields of study, until Brandenburger and Nalebuff published the book Co-opetition. In the book, they argued that co-opetition is the simultaneous competition and cooperation 
between enterprises, and applied game theory to the analysis of co-opetition [1]. From that point on, the subject of co-opetition has been gaining more scholars' attention. At present, studies on co-opetition have focused on the following segments: the definition and formation of co-opetition (Bengtsson and Kock, 1999; Ge, 2006; Huang, 2009; Sun et al., 2009), Classification of co-opetition (Bengtsson and Kock, 2000; Luo, 2005; Yang et al., 2009), Extent of co-opetition (Tsai, 2002; Garcia et al., 2002; Gnyawali et al, 2006; Luo, 2006; Li J., $2008 \mathrm{Xu}$, 2009. Li C. F., 2013), evolution and maintenance of co-opetition (Bengtsson et al., 1999; Abuja et al., 2002; Mariani, 2007; Zhong, 2007; Zhao, 2007; Li W. et al., 2010), and performance of co-opetition (Ji et al., 2000; Levy et al., 2003; Garcia and Velasco, 2004; Cristina et al., 2004; Ma, 2004; Chen et al., 2010). However, most papers have focused on theoretical analysis, while few have applied the theory to specific industries. In the field of agricultural economics, a number of studies have applied the theory of co-opetition to the swine industry (Wang, 2008; Sun, 2009), but none has applied the theory to the edible mushroom industry. Moreover, the subject of co-opetition studies has always been large-scale corporations, with most concenring multi-national enterprises (MNEs), (Dagnino and Padula, 2002; Luo, 2007) and only a few concerning small and medium enterprises (SMEs). In fact, SMEs have very limited access to resources, and their bargaining power is weak, and they face higher market risks [2]. Therefore, their tendency to seek forming cooperative relationships is relatively high, as co-opetition means access to more resources, reinforcement of market power, entrance to new markets and so on [3].

During the last few years, the industrial structure of China's edible mushroom industry has undergone a fundamental change; the number of large-scale enterprises that engage in commercial cultivation of edible mushrooms (simply referred to as "enterprises" in this paper) has been growing at a rapid speed. According to statistics from China Association of Edible Mushrooms, the number of large-scale enterprises in Shandong province has increased from around 20 in 2010 to 120 in 2013, with an annual growth rate of $81.71 \%$. However, according to Shandong Association of Edible Mushrooms, small-scale farmers who engage in household production of mushrooms (simply referred as "farmers" in this paper) take up to $85 \%$ of the domestic edible mushroom output. The edible mushroom cultivation in China is still dominated by farmers instead of the fast growing enterprises. It can be concluded that the co-existence of enterprises and farmers has been and will be the long-term status quo of the edible mushroom industry in China. Under this status, the development of enterprises has brought fierce competition to the industry, threatening the survival of farmers. Furthermore, the number of enterprises has been growing rapidly, leading to fierce price competition among enterprises, which in turn resulted in a lower market price, lower profit margin, and higher rate of bankruptcy. Balancing the competition between and development of the two has become a pressing issue. This paper argues that forming cooperative relationship between the two can facilitate a 
synergistic effect, maximize profit and promote a healthy development of the edible mushroom industry.

\section{Effect of Co-Opetition on Industrial Competition Pattern}

The formation of a cooperative relationship between large-scale enterprises and small-scale farmers will transform the competition pattern of the industry. Before cooperative relationship is formed, the two are direct competitors. Applying Michael Porter's Five Forces Model (see Figure 1), large-scale enterprises and small-scale farmers are "industry rivalry", both facing competition from suppliers (namely raw material providers, production equipment providers and technology supporters, etc.), buyers (namely wholesale markets, supermarkets and end customers), potential entrants and substitutes (namely meat and vegetable producers). Provided all four other forces remain constant, after the formation of a cooperative relationship, the relationship between enterprises and farmers change from industry competitors to co-opetition partners, who are simultaneously cooperators and competitors. Competition between them changes as well, from peer competition in product market to competition along the value chain. Specifically, enterprises become suppliers for farmers by providing growing bags, fertilizers, pest control facilities, pesticide, technical support, marketing services, etc. At the same time, they are buyers from farmers as they purchase final edible mushroom products from them. It is the same for farmers; they buy production materials and services from enterprises while selling final products to them. Now instead of competing in product market, the two compete along the value chain to acquire resources and divide profits, and compete with the other four forces of competition as a whole, forming a new competition pattern for the edible mushroom industry (see Figure 2).

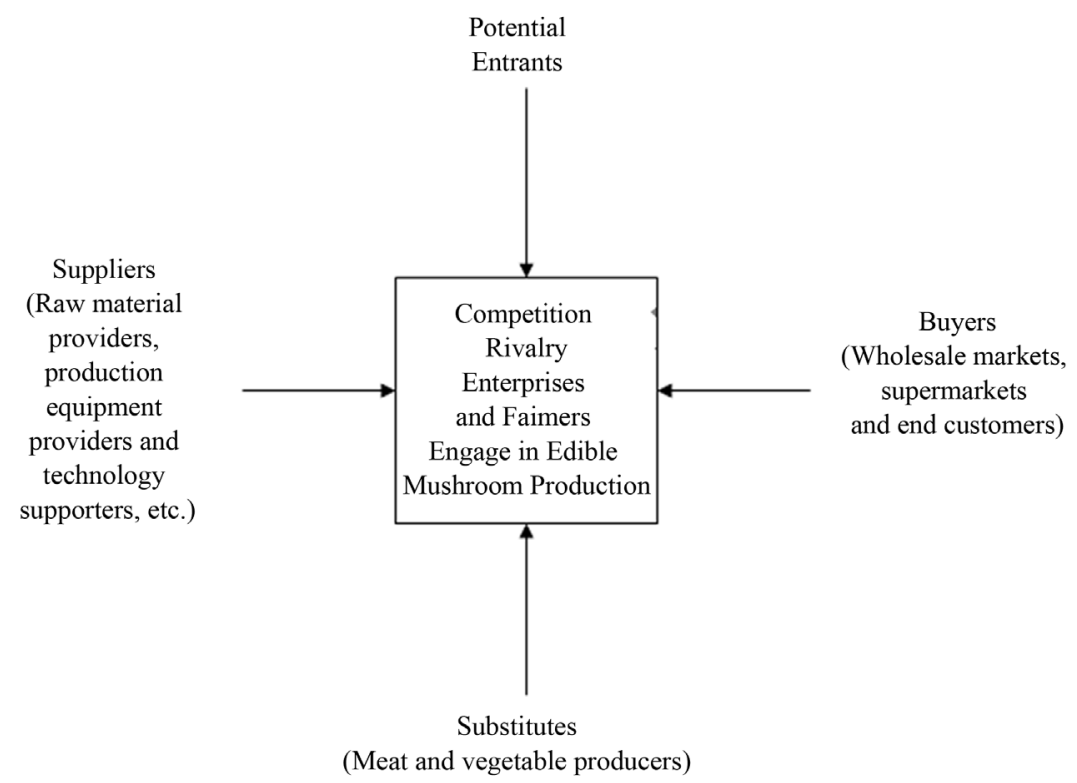

Figure 1. Basic competition pattern in edible mushroom industry. 


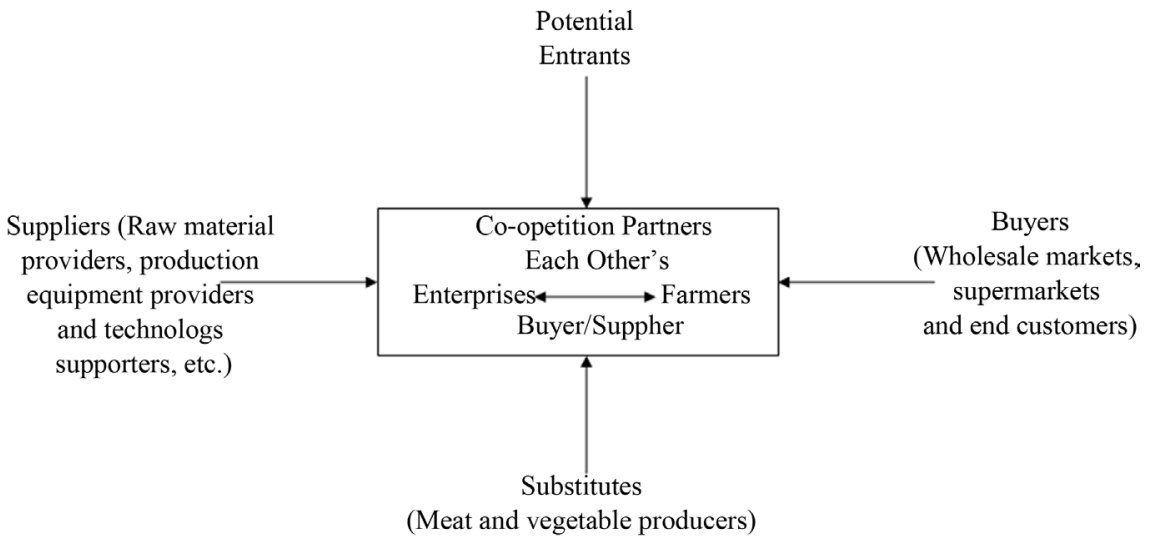

Figure 2. Competition pattern under co-petition in edible mushroom industry.

\section{Motives for Co-Opetition}

\subsection{Resource Dependence Motive for Co-Opetition}

According to the resource dependence theory, in order to survive and thrive, firms have to only attain certain amount and types of resources. However, resource scarcity dictates that a firm has only limited access to resources and cannot acquire all the resources it needs; thus cooperation between different resources holders will come into being [4]. In the edible mushroom industry, enterprises enjoy advanced production techniques, more market information, strong bargaining power, diversified sale channels and sufficient financial support; while farmers are equipped with low cost production (mainly cost of labor, land, supervision and motivation and internal management) and high flexibility in entering and exiting the market, adjusting scale of production and so on [5]. In contrast, enterprises are faced with relatively high production costs and low flexibility, while farmers suffer from outdated production techniques, low bargaining power, limited market information and sale channels. Moreover, as informatization and urbanization advances, the industry environment changes as well; important resources for edible mushroom growers are no longer limited to the usual raw materials and land, as market information, logistics, sales channel and government support have become ever more crucial. Resources owned by enterprises and farmers are highly complementary, and with the industry environment changes, the two will be motivated to cooperate.

Resource dependence also motivates enterprises and farmers to compete with each other. First, to survive and grow, they both need to continuously acquire resources. While resources are scarce, they are natural competitors. Second, the amount of crucial resources owned by enterprises is larger than that owned by farmers, together with the information asymmetry; farmers tend to be more dependent on enterprises in co-opetition. This will increase the chance of opportunistic behavior by enterprises, causing competition between the two.

\subsection{Self-Interest Motive for Co-Opetition}

Under the assumption of homo economicus, both enterprises and farmers are 
motivated by the pursuit of self-interest, in this case, profit maximization. Profit motive leads to cooperation between enterprises and farmers. By cooperating with each other, both are able to interact with each other, take advantage of each other's resources, overcome certain weaknesses, and exploit their competitive advantages to its fullest extent, as to effectively maximize their market share, lower production cost, and maximize profit. Meanwhile, when it comes to benefit distribution, in pursuit of self-interest, enterprises and farmers compete with each other to gain more. The main focus of competition concerns pricing and grading of final products, pricing of various production materials and distribution of profit etc. Also, if disagreements on those issues arise, it could lead to breach of contract from one or both parties, which will result in competition on product market from the two. Moreover, when in co-opetition one or both parties cannot achieve marginal profit that is higher than marginal cost, opportunistic behavior could occur [6], leading to competition between enterprises and farmers.

\section{Benefits of Co-Opetition between Enterprises and Farmers}

\subsection{Benefits of Cooperation}

Benefits of cooperation between enterprises and farmers include but are not limited to: complementing each other on distribution of resources, achieving synergistic effect, improving production efficiency, lowering cost and increasing market share.

By cooperating with farmers, enterprises could achieve lower cost and higher flexibility of production. First, constrained by the biological properties of edible mushrooms and machinery limitations, edible mushrooms cultivation process is not fully automated, need for manual labor is still intensive, causing relatively high labor cost. Plus, enterprises have more complex organizational structures, resulting in higher overhead costs for management, marketing and technique personnel. In contrast, for farmers, it is family members who engage in edible mushroom production, cost of labor is usually not calculated separately. Moreover, farmers usually act as working labor and management personnel themselves, and no extra cost of labor applies. Second, unlike industrial production, production of edible mushroom is more complex and the growing of mushrooms is affected by various factors, causing the contribution of labor to the final product difficult to quantify. This may give rise to low work efficiency and high supervision difficulty, causing motivation and supervision cost to rise. In contrast, farmers usually are more efficient workers in that the work they put in during production directly affects the output and quality of final mushroom products, which determines how much money they make. Also, family members in a farmer's household are bonded by non-economic factors, they have a strong sense of identity and are highly motivated, reducing the need for and the cost of supervision and motivation. Third, enterprises' flexibility of production is con- 
strained by large amount of fixed asset investment and cost of idle assets. Cooperating with farmers enables them to flexibly enlarge and reduce scale of production without having to bear high marginal fixed asset cost or cost of idle assets.

During the production of edible mushrooms, production of growing bags is one of the most important processes. The quality of growing bags has substantial influence on the yield and quality of the final product in that the following ways; the proportion of various raw materials in the substrate inside growing bags significantly impacts the yield of mushrooms; improper sterilization of growing bags increases the risk of bacterial infections; quality of mushroom strains incubated in growing bags affects yield and quality of final mushroom products. Growing bags made by farmers often suffer quality issues including disproportional substrate, improper sterilization and use bad quality strains. The low quality of growing bags exposes farmers to higher production risks. In a cooperative relationship, taking advantages of advanced technology, automated production equipment, strong bargaining power for raw materials, enterprises are able to provide farmers with high quality growing bags at a relatively low cost, which simultaneously improves the yield and quality of mushrooms and reduces production risks. Second, fresh mushrooms are highly perishable. Due to financial limitations, farmers cannot afford refrigerated transportation and storage, causing fresh mushrooms to spoil and degrade, adversely affecting their earning capacity. By cooperating with enterprises, farmers are able to take advantage of enterprises' refrigerated transportation and storage, extending shelf life of fresh mushroom and increasing their earning.

\subsection{Benefits of Competition}

Besides cooperating, enterprises and farmers compete as well. Competition between the two could give rise to more efficient and specialized distribution of resources. In the case of co-opetition, farmers are in charge of the labor-intensive production processes, while enterprises are in charge of the information and technology intensive processes such as marketing, which leads to an efficient distribution of resources. Competition between the two in regards of profit sharing can improve overall efficiency and equality. On one hand, when disagreements and conflicts occur, efforts will be made to settle disagreements and solve conflicts. During the settlement, understanding comes with frequent communication, which will enhance trust and commitment of the two and improve overall efficiency of co-opetition. On the other hand, full competition and settling on profit sharing can perfect the profit sharing system, resulting in enterprises and farmers receiving fair and equitable share of the profit.

Most research considers farmers as a whole when studying the relationship between farmers and firms. However, a fact that is often ignored is that farmers are competitors among themselves. Every individual farmer seeks his or her own self-interest, so when cooperating with enterprises, they compete with one 
another for the crucial resources offered by the enterprises. The existence of competition fosters mutual supervision among farmers, suppresses farmers' opportunistic behaviors, ensures product quality and improves co-opetition efficiency. A simplified game with two farmers can illustrate this phenomenon. (See Figure 3) Assume that 1) farmers A and B are rational agents, they make rational decisions in the pursuit of self-interest; 2) farmers gets paid by the enterprise if they honor the contract; 3) farmers have to pay a fine to get out of the contract. In this example, there are two choices, choice one $(\mathrm{C} 1)$ is to honor the cooperation contract between enterprises and farmers, choice two (C2) is to pay a fine to be released from the binding contract. The payoff for $(\mathrm{C} 1, \mathrm{C} 1)$ is the highest, making it the dominant equilibrium of this game. To sum up, competition among farmers helps maintain cooperation between farmers and enterprises.

\section{Potential Challenges of Co-Opetition}

\subsection{Enterprises Could Be Exposed to Higher Uncertainty of Revenue}

In a cooperative relationship, enterprises purchase final mushroom product from farmers according to a contracted price. There are normally two kinds of contract price, one is a fixed price agreed upon by both parties, and another is fair market price at the time of purchase. When the product is purchased at a fixed price, (See Figure 4) since the price is agreed by both parties, the price Pf is considered to be higher than farmers' cost of production Cf. In this case, farmers will at a minimum have revenue of Rf, regardless of the relationship between contract price and market price. However, when the market price is $\mathrm{Pm}^{\prime}\left(\mathrm{Pm}^{\prime}<\right.$ $\mathrm{Pm})$, revenue of enterprises is Re', and they suffer from a loss of Rf-Re'. When the contract price is fair market price (see Figure 5), assume both party enjoys revenue of $\mathrm{R}$, now both of them face uncertainty of revenue. Specifically speaking, when market price $\mathrm{Pm}<\mathrm{Cf}$, both party are at loss; when market price is Pm' ( $\mathrm{Cf}<\mathrm{Pm}$ ' $<\mathrm{Ce}$ ), enterprises are at a loss of Ce- $\mathrm{R}$ while farmers still make a profit. When market price is $\mathrm{Pm}$ " (Pm" > Ce), both parties make a profit. When operating without farmers, enterprises only suffer from a loss when the market price is lower than their cost of production. It can be concluded that, after forming a cooperative relationship with farmers, a certain degree of farmers' revenue uncertainty is shared with the enterprises, exposing the enterprises to

\begin{tabular}{|c|c|c|c|}
\hline & & & \\
\hline & & Defect & Defect \\
\hline & Cooperate & 0,0 & $0, \mathrm{f}$ \\
\hline & Cooperate & $\mathrm{f}, 0$ & $\mathrm{f}, \mathrm{f}$ \\
\hline
\end{tabular}

Figure 3. The payoff matrix. 


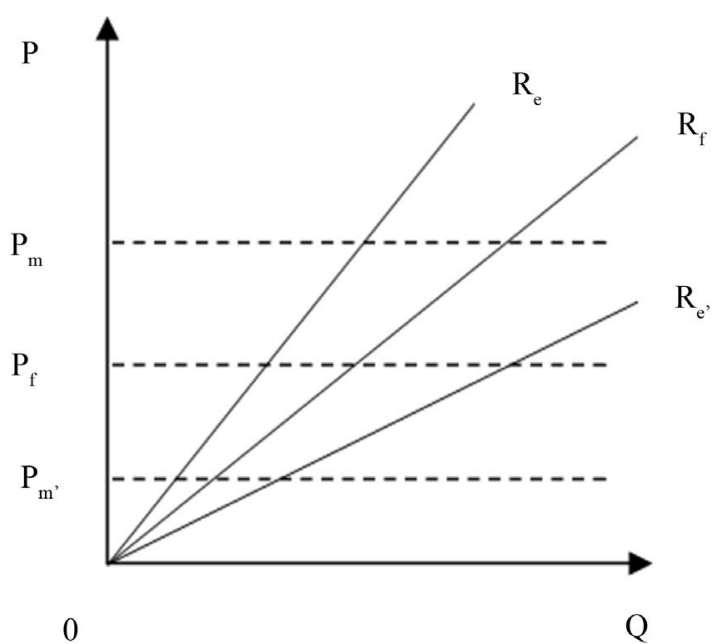

Figure 4. Mushroom purchase at fixed price $P_{f}$

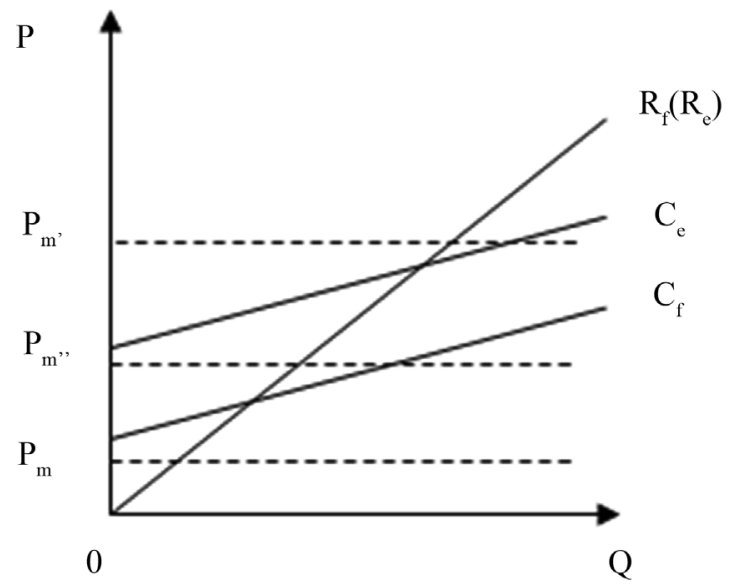

Figure 5. Mushroom purchase at market price $P_{m}$.

higher risks. Additionally, according to price statistics acquired from wholesale markets in Shandong by our research group, edible mushroom market price fluctuates significantly: five out of the top ten best-selling edible mushroom products has a fluctuation rate of more than $10 \%$ (see Table 1). Unstable market prices bring even more uncertainty to enterprises in a cooperative relationship with farmers, and challenges the maintenance of cooperative relationship.

\subsection{Management and Coordination Cost for Enterprises May Increase}

In the process of co-opetition, in order to promote co-operation and resolve conflicts, enterprises and farmers are exposed to management and coordination costs, which include communication cost, information cost, bargaining cost, etc. A major portion of the internal management costs is borne by enterprises. First, due to the small production scale and large number of farmers, during co-opetition, one enterprise has to keep contact with each farmer individually, provide 
Table 1. Fluctuation of fresh edible mushroom price in shandong, China as of 2014 (Unit: CNY/kg).

\begin{tabular}{ccccc}
\hline Variety & Highest Price & Lowest Price & Annual Avg. price & Fluctuation (\%) \\
\hline Enokitake Mushroom & 12.8 & 3.9 & 6.6 & 26.5 \\
Hypsizygusmarmoreus & 17.8 & 7.5 & 11.2 & 12.9 \\
King Oyster Mushroom & 11.9 & 5.6 & 7.8 & 12.2 \\
Columnar Agroc & 16.8 & 10.5 & 12.2 & 11.9 \\
Pleurotusgeesteranus & 14 & 7.5 & 9.7 & 10.8 \\
Oyster Mushroom & 7.5 & 1.4 & 64.2 & 6.0 \\
Shaggy Mane & 11 & 7.5 & 9.8 & 5.6 \\
Shii-take Mushroom & 14 & 6.7 & 10.1 & 2.5 \\
Button Mushroom & 11.8 & 8.5 & 10.3 & 1.5 \\
Hypsizygusmarmoreus & 20 & 11 & 15.4 & 0.6 \\
\hline
\end{tabular}

* Source: edited data from field research and China Edible Mushroom Business website (http://www.mushroommarket.net/).

production guidance and assistance to individual farmers depending on their specific production conditions, thus leading to a significant rise in management and coordination costs [7]. Second, as co-opetition forms, the size of an organization expands, hierarchies increase, and the process of communication and information transfer becomes more complicated, which gives rise to the possibility of information distortion, resulting in a decline in communication efficiency and rise in management and coordination costs. Third, even though enterprises are usually the leaders in a cooperative relationship, enterprises and farmers are equal in status, as such rather than forcing their production disciplines or decisions on farmers, enterprises have to actively communicate and coordinate with individual farmers, resulting in an increase in coordination costs. Fourth, motivated by personal interest maximization, and further aggravated by non-mutuality of interests, disagreement, conflicts or even breach of contract between enterprises and farmers are inevitable to some degree. In order to keep co-opetition going, time and effort must be made to settle any disagreement and conflicts, causing coordination cost to grow. Finally, in the edible mushroom value chain, enterprises and farmers are not tightly related, and value points between them are not substantial, leaving room for opportunistic behavior, which may lead to extra management and coordination costs.

\subsection{Exit Cost May Become More Significant for Farmers}

When growing edible mushrooms by themselves, small-scale farmers' exit cost is low, as their cost of fixed assets is relatively low. After forming a cooperative relationship with enterprises, farmers' barriers to exit the edible mushroom industry may become more significant than before, in that both cost of fixed assets and asset specificity increases, leading to rise in exit cost. The largest investment 
in fixed assets for small-scale farmers is the mushroom growing sheds. Farmers normally build simple and basic mushroom growing sheds, which require relatively low investment and takes short time to recover the cost. While after forming cooperative relationship with enterprises, farmers are usually required by enterprises to renovate or even rebuild growing sheds, with implementation of mushroom shelves, pest control facilitation, temperature control devices and ventilation equipments, etc. Added investment in fixed assets increases sunk cost for farmers which in turn raise their barriers to exit. According to the field research of a co-opetition program in Shenxian County, Shandong Province, a growing shed that takes up about $200 \mathrm{~m} 2$ bears a building cost of 30,000 to 40,000 Chinese Yuan, while the cost of a newly renovated shed of similar size reaches up to 150,000 Chinese Yuan. In addition, due to the installation of growing shelves and specific equipment, asset specificity increases, meaning growing sheds cannot be used for cultivation of other crops. A case in point is that in some areas, when the season for mushroom growing passes, growing sheds are used to grow vegetables. But as the asset specificity of growing sheds increases, the sheds are left unutilized for a certain period of time every year, causing a rise in opportunity cost, and raising barriers to exit for farmers.

\subsection{Partial Loss of Autonomy and Flexibility in Production for Farmers}

In a cooperative relationship, farmers may suffer from partial loss of autonomy and flexibility in production. Enjoying strong bargaining power, advanced technology and production equipments, comprehensive market information, enterprises are normally in the leading role when it comes to decision-making such as choosing mushroom variety, deciding production scale, taking pest control measures and so on. Farmers are usually forced to abide by whatever decisions enterprises make, leading to partial loss of autonomy in production decisionmaking. In addition, farmers' production flexibility is compromised to certain degree. On one hand, due to partial loss of autonomy, farmers are unable to independently decide what mushrooms to grow and at what production scale, leading to less production flexibility. On the other hand, as a result of higher investment in fixed assets, flexibility in adjusting the scale of production and entering and exiting market is weakened. Farmers with less autonomy and flexibility in production may grow to be more dependent on enterprises, causing some of the risk in decision failure to transfer to farmers, thus increasing the possibility of opportunistic behavior from enterprises which puts the cooperative relationship at risk.

\section{Institutional Evolution and Optimization of Co-Opetition}

\subsection{Institutional Evolution of Co-Opetition}

Depending on the level of competition and cooperation, co-opetition can be divided into the following three categories, competition based co-opetition mode, 
cooperation based co-opetition mode, and balanced co-opetition mode (See Figure 6). Competition based mode is the most inefficient co-opetition mode, cooperation based mode enjoys slightly more efficiency, while the balanced mode enjoys the highest efficiency among the three, making it the ultimate goal of institutional evolution for cooperative relationships. There are two paths of evolution for different modes of co-opetition, the first path one the "competition based-cooperation based-balanced mode" sequence, and the second path follows the "competition/cooperation based-balanced mode" order. In light of that, the ultimate goal for co-opetition between edible mushroom farmers and enterprises should be the realization of a balanced co-opetition partnership.

In real life, competition based mode, which lacks cooperation, is the most widespread type of co-opetition partnership between farmers and enterprises engaged in edible mushroom production. This mode can stimulate both parties to bring their competitive advantages into full play. However, under this model, the parties mostly operate independently, seldom cooperating with each other, production risks are be shared or diminished, and competitive disadvantages are be made up, causing limited overall competitiveness and efficiency. In the past couple of years, constrained by factors such as complicated production technology and limited sales channels, a large number of small-scale farmers have exited the edible mushroom industry. On the other hand, a number of large-scale enterprises went bankrupt because of high production cost and low profit margin. Improving cooperation between the two can stimulate a synergy effect, promoting cooperative efficiency, and pushing the competition based mode to evolve into a higher level of co-opetition.

\subsection{Optimization of Co-Opetition}

The current state of the edible mushroom industry in Shandong Province is that, competition based mode is the most widespread type of cooperative relationship, there is more than enough competition but inadequate amount of cooperation involved. Therefore, the goal of promoting cooperation should be prioritized for policy making consideration.

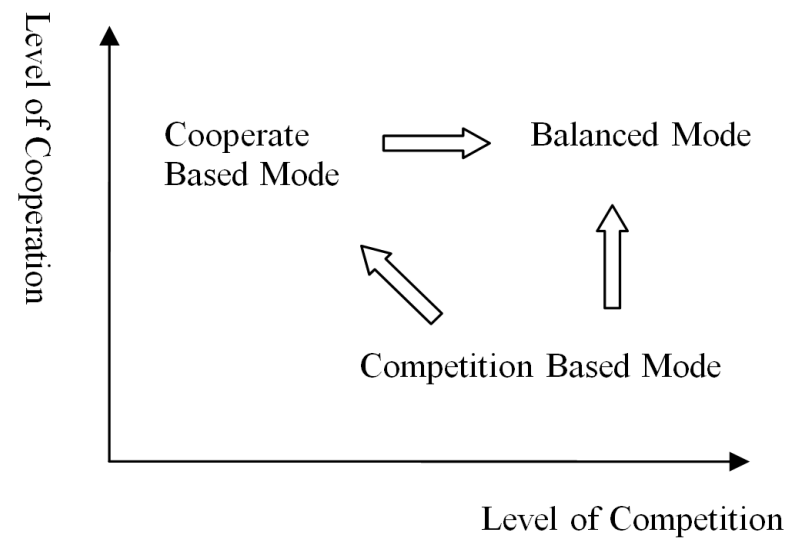

Figure 6. Classification and Evolution of Co-opetition. 


\subsubsection{Promoting Edible Mushroom Price Insurance}

Launch of price insurance could contribute to cooperation between enterprises and farmers. One of the main challenges for co-opetition between enterprises and farmers is that enterprises are exposed to higher revenue uncertainty. Based on previous research, edible mushroom prices frequently and widely fluctuate, together with the transferred price risk from farmers, enterprises face high level of uncertainty of income, which in turn, reduces their willingness for cooperation. With price insurance, insured enterprises or farmers can get compensated when market price is low. This largely reduces income uncertainty, leading to stronger willingness to cooperate from both parties. Additionally, the promotion of price insurance is relatively easy compared to other financial price adjustment tools such as options and futures in that enterprises and farmers do not need much financial knowledge to buy price insurance. At present, there have already been some development in price insurance in China, and price insurance has become one of the important aspects of Chinese agricultural policy making. Specifically, the No.1 Central Document of 2014 stated that: "target price system for agricultural produce must be established gradually, which subsidizes producers with the price difference when market price is lower than the target price, ensuring farmers' income. In 2014, target price subsidy for cotton will be launched in three provinces in Northeast China, and other experimental price insurance programs involving cereal crops and hogs will be launched." [8]. As of February 2015 , price insurance programs involving cereal crops, hogs and vegetables have been launched in 20 provinces of China [9].

\subsubsection{Developing Edible Mushroom Cooperatives}

Enterprises and farmers in the edible mushroom industry suffer from low efficiency under the competition based co-opetition mode due to inadequate cooperation, which restrains the optimization of resources and maximization of overall benefits. The crucial element in promoting cooperation lies in enhancing the willingness to cooperate. Opportunistic motives along with management and coordination cost have adverse effects on the willingness to cooperate. Opportunistic motives, incomplete contracts, asymmetry of information and disproportional distribution of benefits may lead to non-cooperative behavior from farmers. [10] Through cooperatives, farmers who engage in small-scale production of edible mushroom can organize. Thus, their bargaining power can be strengthened, their autonomy and flexibility in production can be recovered to a certain degree, enabling farmers to obtain more market information, fight for reasonable share of profits, and promoting their willingness of cooperation. Cooperatives can promote farmers' willingness to cooperate with enterprises, as well as supervise and manage farmers, suppress their opportunistic motives and behaviors. In addition, cooperatives bear the cost of organizing and managing geographically scattered farmers, reducing management and coordination cost for enterprises, which can effectively increase enterprises' willingness to cooperate, promoting the evolvement of co-opetition toward the ultimate balanced 
mode.

\subsubsection{Strengthening Government Support}

As a mandatory institutional change factor, governmental support plays a crucial role in the institutional evolution of co-opetition partnership to the ultimate balanced mode in the edible mushroom industry. In real life, it is normally enterprises rather than small-scale farmers engaging in edible mushroom cultivation who initiate the formation of co-opetition. According to a survey of edible mushroom enterprises in Shandong Province, $41.67 \%$ of enterprises admitted that the prominent motive for initiating cooperative relationship with farmers is due to "Government support" ${ }^{\text {, }}$ most of these enterprises receive subsidies, financial support and tax exemptions from central, provincial, county and/or local governments. It is safe to conclude that governmental support plays an important role in promoting the co-opetition between small-scale farmers and large-scale enterprises. Current governmental support policies are mostly subjected to "leading agribusiness" (a large scale enterprise engaged in agriculture production that can largely contribute to local economic development), even though there is a large number of enterprises engaging in edible mushroom production, few qualify as a "leading business", and thus most are unable to benefit from the governmental support policies. In addition, existing support policies attempt to increase farmers' benefit indirectly through supporting "leading agribusiness", resulting in "rent-seeking" to a certain extent, failing to actually benefit farmers [11]. Therefore, to justify its actual purposes, governmental support should directly target farmers, as well as a wider range of enterprises.

\section{References}

[1] Brandenburger, A. and Nalebuff, B. (1996) Co-Opetition: A Revolution Mindset That Combines Competition and Cooperation. Harvard business Press, Cambridge.

[2] Levy, M., Loebbecke, C. and Powell, P. (2003) SMEs, Co-Opetition and Knowledge Sharing: The Role of Information Systems. European Journal of Information, 12, 3-17. https://doi.org/10.1057/palgrave.ejis.3000439

[3] Thomason, S., Simendinger, E. and Kiernan, D. (2013) Several Determinants of Successful Coopetition in Small Business. Small Business Enterprises, 26, 15-28. https://doi.org/10.1080/08276331.2012.761800

[4] Pfeffer, J. and Salancik, G.R. (1978) The External Control of Organizations: A Resource-Dependence Perspective. Harper \& Row, New York.

[5] Li, M. and Hu, J.L. (2014) Study on Survival Strategies of Farmers Engage in Small-Scale Household Cultivation of Edible Mushrooms: Take Shandong Province as an Example. Modern Economy, 5, 1092-1100. https://doi.org/10.4236/me.2014.512100

[6] Gong, H.T. and Gao, Q. (2010) The Economic Analysis of the Optimal Number between Agriculture-Related Leading Enterprise and Farmers. Finance and Economics of Xinjiang, 2, 44-48.

${ }^{1}$ Other motives for initiating co-opetition with small-scale farmers are, "lower production cost", $33.3 \%$; "enlarge scale of production", 16.67\%; "promote regional economics", $8.33 \%$. 
[7] Huang, A.S., Zhang, C.X. and Xie, Z.Z. (2008) The Analysis of the Optimal Scale of Forestry Stock Cooperation System Management: Involving Coordination Costs. Issues of Forestry Economics, 18, 414-418.

[8] Bengtsson, M. and Kock, S. (2000) Competition in Business Networks to Cooperate and Compete Simultaneously. Industrial Marketing Management, 14, 178-193. https://doi.org/10.1108/08858629910272184

[9] The State Council of People's Republic of China (2014) Suggestions on Major Issues Concerning Deepening the Rural Reform and Promoting the Modernization of Agriculture.

[10] He, Y.X. (2015) China Insurance Regulatory Commission: Experimentation of Price Insurance for Agricultural Produce Has Been Implemented in 20 Provinces. http://news.xinhuanet.com/2015-02/20/c_1114408946.htm

[11] Liu, D.J., Yang, H. and Yin, Z.H. (2014) Study on Influential Factors of Non-Cooperative Behavior of Farmers and Leading Enterprises: Based on Survey Data of Farmers in Jiangxi Province. Statistics \& Information Forum, 29, 63-68. 